\title{
POR UMA POLÍTICA PÚBLICA DE COMUNICAÇÃO EM SAÚDE*
}

\section{Aurea da Rocha Pitta**}

RESUMO: A comunicação é um tema estratégico quando se tratam de políticas públicas, em especial a saúde. Os meios de comunicação de massas, em particular a televisão, veiculam notícias de saúde com grande ênfase no discurso clínico e biomédico. Esses temas são, em geral, pautados por interesses das grandes empresas de equipamentos, medicamentos e serviços médicos chegando, por isso, a determinar as pautas das programações de instituições públicas de comunicação como as televisões educativas. Torna-se necessário, portanto, desenvolver pesquisas e trabalhos tendo em vista recolocar na esfera pública o conceito ampliado de saúde na ótica da promoção e como direito de todos os cidadãos. O direito à comunicação vem sendo vocalizado pelos setores populares e segmentos de profissionais de saúde comprometidos com a inclusão de discursos excluídos na mídia numa perspectiva de democratização da informação.

PALAVRAS-CHAVE: saúde, comunicação, políticas públicas, movimentos sociais, jornalismo

\footnotetext{
* Apresentado na Mesa Redonda: Mídia, Saúde e Democracia, em 01/01/01 no VII Congresso Paulista de Saúde Pública.
}

** Jornalista, Doutora e Pesquisadora da FIOCRUZ. 


\section{INTRODUÇÃO}

O tema Comunicação é um tema estratégico que todos nós pautamos para todos os campos das políticas públicas, especialmente para a Saúde, e é um prazer ver o tema assumir relevância num Congresso com a expressão do Congresso Paulista de Saúde Pública. Falou-se da importância da manifestação, da forma com que a mídia expressa os anseios da sociedade, ou às vezes não expressa. Eu queria contar casos. Eu cheguei a essa carreira de pesquisadora na área de saúde pública e no Departamento de Comunicação e Saúde, movida por uma angústia fundamental, depois de ter sido profissional radialista; trabalhei durante oito anos na TV Educativa do Rio de Janeiro, como apresentadora de programas educativos na área de saúde e apresentadora de programas jornalísticos. Essa minha trajetória por dentro dos meios de comunicação, depois de ter passado por salas de aula, dez anos de ensino de Biologia - porque eu sou bióloga de formação - me angustiou bastante, porque eu ia acompanhando diariamente os processos de produção da notícia. Como locutora - eu era uma simples expositora daquilo que os jornalistas me davam para ler - eu acabei me intrometendo no processo de produção da notícia, talvez até demais, por isso fui mandada embora da TV Educativa. Essa convivência com a experiência concreta na área de jornalismo, me fez começar a ler um pouco sobre Teoria da Comunicação. Acabei saindo da área de ensino para trabalhar na área de saúde pública, porque a minha formação é uma coisa completamente heterodoxa, porque eu sou uma bióloga que fiz Mestrado em Saúde Pública, fui locutora de televisão e acabei, claro, num Doutorado em Comunicação e Cultura, tentando fazer uma análise do significado da comunicação para o campo da saúde pública, para o campo da saúde coletiva.

\section{REVENDO AS POLÍTICAS DE COMUNICAÇÃO}

A primeira questão com que eu me deparei quando cheguei na área de saúde pública na Fundação Oswaldo Cruz, eu fui para lá para organizar uma distribuidora de vídeos no início da década de 90, governo Collor de Melo, onde os planos de comunicação, as políticas de comunicação do governo eram políticas behavioristas; mudar o comportamento da população para melhorar as condições de saúde, aquela coisa bem tradicional das políticas de comunicação da década de 40 , dos modelos teóricos de comunicação da década de 40. Isso começou me angustiar bastante e eu comecei a trabalhar um pouco com as teorias, tentando delinear melhor o quê que seria essa comunicação em 
saúde que todo mundo falava mas que acabava sendo sempre alguma coisa educadora de cunho condutivista: eram sempre programas verticalizados, campanhas publicitárias, e essa coisa toda. Me chamou muito a atenção, no início dos anos 90, quando o Collor assumiu a presidência da República, as campanhas do Zé Gotinha, as campanhas de vacinação. $O$ Zé Gotinha começava a vir travestido de Collor de Melo, quer dizer, o Zé Gotinha manejava jet-ski muito bem, jogava muito bem futebol, e essa mistura entre a questão da saúde e a legitimação de um governo eleito me chamou também bastante atenção.

Essa trajetória na TV Educativa me fez também entender as políticas de comunicação no campo da saúde não como políticas educativas e educadoras, mas tentar fazer uma projeção mais ampla, fazer um foco de câmera mais amplo para entender uma discursividade sobre saúde, os discursos em saúde na esfera pública, e a determinação desses discursos nessa esfera pública. Porque você pega o jornal cotidianamente, e é paulada no SUS ou então uma ênfase bastante grande num discurso biomédico; o clone, por exemplo, a clonagem é o grande tema da moda, e algumas coisas que são prioridades em termos de problemas de saúde concretos da população são absolutamente silenciadas. Então essa foi uma primeira preocupação, a de tentar ampliar o foco da câmera, abrir o zoom da câmera para olhar não só as políticas setoriais de comunicação como as políticas educadoras da população, e como teriam determinantes econômicos e políticos por trás delas.

Mas o que eu queria hoje especialmente tratar, é que a gente discute muito comunicação dessa forma mais ampla, trabalha muito com conceitos, todo mundo sabe que há monopólio das comunicações no país, sabemos que temos que lutar contra esse monopólio, que esse monopólio é determinante na falta de expressão da população, dos movimentos sociais em saúde na esfera pública, a gente sabe disso tudo. Eu queria tentar fazer uma reflexão e aproveitar o momento para analisar um ou dois casos do interior da máquina, da estrutura, por exemplo, da televisão, e de como ela se expressa no campo da saúde. Primeiro caso: fui convidada para fazer um programa, faz uns cinco anos mais ou menos, chamado "De Olho na Saúde", na TV Educativa. Concordei em apresentar o programa desde que, como pesquisadora da FIOCRUZ, a gente pudesse discutir a pauta do programa, porque quando eu olhei o programa no ar era assim: convidar um médico para falar sobre doença, remédio, medicamento, cuidados, exclusivamente em assistência médica e clínica. Com essa nossa discussão de conceito ampliado de saúde, saúde como direito de todos, promoção da saúde, políticas intersetoriais de saúde, eu resolvi tentar mexer na estrutura do programa, e claro que eu não consegui, porque existe uma cultura no interior da instituição televisão. Ela é uma instituição como outra qualquer; você tem uma rede de relações de 
força e de poder bastante grande, tem uma cultura de processos de trabalho muito bem estruturados, tipo modelo taylorista mesmo, aquela coisa arrumadinha, cada um tem uma função, o chefe manda aqui, você tem que falar isso, então você tem uma estrutura bastante autoritária em termos de produção, e essa estrutura acaba determinando o quê que sai dali em termos de discurso em saúde, que é uma cultura bastante privatista em termos de definição do quê dizer. Eu trabalhei numa televisão educativa, que é uma televisão até certo ponto... é uma estatal, devia ser pública mas é estatal, e aí a gente vai começando a se deparar com a questão do modelo de gestão, de gestão do discurso que essa televisão expressa. Isso foi a coisa que mais me deixou assim espantada ...

A forma com que os interesses privados vão manejando de maneira sutil e às vezes ardilosa o processo de trabalho por dentro da televisão é que fazem com que essa coisa seja definida para além de critérios que são públicos. Você ocupa o espaço público, você tem uma concessão pública, como a TV privada ou como a TV educativa mesmo, que é TV do governo, e os processos no interior dessa TV, os processos de gestão discursiva do que essa TV vai colocar para a população são processos absolutamente privatistas. Exemplo: estava eu um dia tentando remexer a pauta do programa e convencendo a equipe de produção que a gente precisava fazer uma articulação, pelo menos com o Conselho Nacional de Saúde, o Ministério da Saúde, essas manias que a gente tem de tentar abrir o leque dos discursos e incluir socialmente outros discursos que não são considerados válidos pela televisão. Um dia eu estava tentando fazer algum tipo de pauta que eu já não me lembro mais e a pauta da TV tinha que ser obrigatoriamente hiperatividade em crianças. Eu digo: "Mas meu Deus, por quê que a pauta tem que ser hiperatividade em crianças, nesse momento? Tem a sua relevância pública, vai ser tratado, mas por quê esse e não algum outro tema que seja um tema de interesse epidemiológico mais contundente ou alguma coisa que a gente possa pescar no SENEP e ver o quê que é que pode ser discutido?". E o retorno da televisão foi que não: "Esse tema é importante porque deu no jornal $O$ Globo", olha só a engenharia. Eu digo: "Mas é o jornal $O$ Globo que pauta a televisão que é pública? Como é que é isso?". E eu fui lá, não consegui convencer ninguém, como locutora e apresentadora do programa fomos fazer um programa de hiperatividade em criança.

Uma semana depois a revista Veja começou a publicar alguma coisa sobre hiperatividade em crianças e aquilo vira um rumor público, alguma coisa que alguém plantou na mídia, e mais uma semana, uma indústria de medicamentos lança um remédio para hiperatividade em crianças, certo? Então é essa intimidade do processo de construção da notícia, é essa engenharia pública que se faz, com que a gente deve ver, ler e prestar 
atenção diariamente e que eu acho que deve ser um incômodo de todos nós. Se você tem uma TV como uma TV pública, estatal, eu acho que a discussão que a gente tem em relação ao modelo de gestão no campo da saúde pública tem que ser introduzida no campo das comunicações. Agora, quando a gente faz isso, o quê que acontece? O pessoal começa a dizer: "Mas isso é censura !"; eu digo: "Mas espera aí, onde é que está o nó dessa história?". Quer dizer, é censura na hora que a gente quer tentar gerir publicamente, introduzir outras vozes, outras culturas no processo de construção de uma pauta pelo menos numa TV que é pública, e não é censura quando a televisão escolhe que não é o seu fulaninho que vai falar, mas o Doutor Xis. Então eu acho que isso é um dos temas da intimidade do processo de produção de discursos para o público que eu acho que a gente deve enfrentar, tentar discutir, porque a gente acaba, nesse campo da comunicação social, a gente acaba despolitizando o tema, colocando a comunicação como uma questão menor ou educadora, de fazer boas linguagens e de bons programas de TV para ensinar o público como deve se comportar e se esquece de que existe uma discursividade mais ampliada sobre saúde, que faz com que o discurso biomédico reincida exclusivamente sobre o público, e que você não tenha a emergência de nenhuma pauta pública, os movimentos sociais estão completamente calados.

\section{POR UMA NOVA POLÍTICA DE COMUNICAÇÃO}

Eu fiz uma análise de alguns projetos de 100 representantes de usuários na Conferência Nacional de Saúde e é um absurdo o que os movimentos sociais no Brasil fazem de malabarismo e de acordos por dentro de pequenas emissoras de rádio e de TV para serem ouvidos, para colocarem alguma coisa de polêmica no ar. Então essa questão da privatização do processo de trabalho em TV, da privatização dos meios de comunicação social, acaba sendo determinante do que se diz em saúde, em público. Então essa é uma primeira questão que eu queria colocar, que tem a ver com a questão da comunicação, da empresa de comunicação como uma empresa que tem um processo de gestão. Ali também acontece um processo de gestão do discurso que está em público, um discurso que acaba determinando um certo acervo de conhecimento ao qual a população tem acesso. A gente não tem outro jeito de saber coisas em público a não ser via meios de comunicação de massa, ou escola, e é claro, também o espaço doméstico, o livro que a gente compra, mas a mídia penetra na casa da gente, nos filhos da gente 24 horas por dia. S e a gente prestar atenção nos últimos acontecimentos em Manhattan, Bin Laden, etc., etc., e prestar atenção 
no que se passa com os filmes na madrugada, da casa da gente, a gente vê que talvez os Estados Unidos tenham sido vítimas da própria loucura que criaram em termos de filmografia de cultura da violência no país. Quer dizer, a América Latina inteira invadida, os nossos lares, os nossos filhos, por uma cultura do armamento, a indústria do armamento está permanentemente ligada, ou falando através das emissoras de TV e da filmografia que a gente tem acesso, que os filhos da gente têm acesso. Eu não sei até que ponto isso é completamente determinante, é claro que o público não é passivo, a gente sabe disso, cada um faz disso o que quer, as pessoas são sujeitos e traduzem o conhecimento que recebem da televisão e refazem essas informações em função do acervo de conhecimentos que receberam na escola, na família, etc. Mas num país com o índice de analfabetismo que a gente tem, o índice de pobreza que a gente tem, os apelos de mercado que a televisão coloca, é o armamento que a televisão coloca cotidianamente. Eu sinceramente pararia dois minutos para pensar pelo menos em colocar a universidade para aprofundar seriamente uma avaliação da eficácia desse acervo cultural a que a gente está exposto, a que os filhos da gente estão expostos diariamente, em relação ao comportamento, e nos Estados Unidos, o próprio Congresso americano, o Senado, etc., têm projetos de avaliação e alguma legislação que regula minimamente isso.

A gente não consegue no Brasil sequer chegar ao que os Estados Unidos chegaram, como país capitalista, em termos de regulação das emissoras de televisão, o que dirá o que algumas emissoras na França e Espanha, etc., já conseguem fazer. Então essa é uma questão menor, que eu acho que obriga quem está na área de saúde pública a não pensar nessa questão da comunicação sem passar por uma articulação com o Legislativo. Eu acho que é obrigatório hoje, na hora de você discutir políticas de comunicação na saúde no Brasil, e verificar até que ponto esse acervo que se estrutura, de conhecimentos em relação à saúde, à violência, à cultura do corpo, ao silicone, a todas essas loucuras que a gente tem hoje nas mãos dos nossos filhos, por exemplo; a minha filha pequena está em crise porque os seios não crescem muito, então a cultura hoje em dia das meninas é que os seios têm que ser imensos, é uma coisa assim de alucinar. Eu acho que quem trabalha na área da saúde, tem uma hora que a gente tem que dar uma paradinha para pensar até que ponto essa coisa não se estrutura via mercado, exclusivamente via mercado, uma cultura sobre o corpo, sobre o prazer, sobre o sexo, você está permanentemente exposto a um apelo midiático que talvez a escola não dê conta, talvez a gente não dê conta em casa de contra-restar, de polemizar com as crianças o tempo todo. Essa é uma coisa mais ampla em termos de discurso em saúde. 


\section{AS POLÍTICAS SETORIAIS DE COMUNICAÇÃO NA SAÚDE}

Uma segunda coisa são as políticas setoriais de comunicação em saúde, esse é um outro ponto complicadinho. Eu tentei, na minha tese de Doutorado, saber do Ministério da Saúde o quê é a política do Ministério em relação à comunicação, e eu vou dizer uma coisa, eu estou há três anos, quando eu vou à Brasília, vou ao Conselho Nacional de Saúde, eu passo no $5^{\circ}$ andar do Ministério, no Gabinete do Ministro, Assessoria de Comunicação Social, não consigo informação nenhuma sobre absolutamente nada. É como se o jornalista tivesse todos os poderes sobre a informação, e aquilo funciona como espaço absolutamente privado; eu sou uma pesquisadora da Fundação Oswaldo Cruz e não tenho acesso a um documento que é um plano de comunicação social do Ministério da Saúde, não se consegue, nem o presidente da FIOCRUZ conseguiu ao tentar intermediar. Bom, minha tese está vazia de conhecimento em relação ao que se faz na Assessoria de Comunicação do Ministério da Saúde, a não ser o que se consegue na Internet, ... e acabou; tive que recorrer ao Congresso Nacional, pegar dados sobre orçamento de campanhas e ficar absolutamente estarrecida com os gastos, por exemplo, que se tem no Ministério da Saúde com publicidade atualmente. Eu não tenho o número exato aqui, mas em relação à campanha de dengue, só de janeiro a março desse ano se gastou no Ministério da Saúde, em produção e veiculação em TV, que é concessão pública, a metade do orçamento da FIOCRUZ, vamos dizer, alguma coisa correspondente à metade do orçamento anual da FIOCRUZ. É uma coisa que não se tem avaliação nenhuma, quem avalia campanha publicitária no Brasil hoje?

Há algumas avaliações na área de AIDS, porque eu acho que o Programa DST/ AIDS avançou bastante em termos de programas, ou de fazer um planejamento minimamente democráticos. Mas quem avalia o impacto de campanhas feitas pelas agências de publicidade hoje no Brasil são as próprias agências de publicidade, é o chamado IAP, é o Instituto de Apoio à Publicidade, que congrega o pool de agências de publicidade hoje, que servem ao Governo. Quer dizer, as agências fazem a campanha e elas se auto avaliam, então é uma coisa complicada, a universidade não tem nada com isso; eu acho que é uma das coisas que, em termos de política de comunicação, a gente precisa estar atento e está completamente alheio. A Escola de Comunicação da UFRJ tem um grupo que tenta se introduzir nessa coisa, mas existe um bloco fechado em termos de campanhas nacionais eu só avaliei campanhas nacionais, não tive tempo de pegar nenhuma estrutura estadual ou municipal - e acho que isso é uma questão fundamental a ser debatida. 
E finalmente, em contrapartida você tem uma expressão das últimas Conferências Nacionais de Saúde - eu analisei as últimas 4 Conferências, desde a $8^{a}$ até $a 11^{\text {a }}$ Conferência, peguei relatórios parciais das Conferências, porque os relatórios finais já estão bem condensados, eu acho os relatórios parciais mais ricos - e o que se diz nas Conferências Nacionais de Saúde, as Conferências elas têm o papel de pautar, em princípio, a política nacional de saúde, o que se diz sobre comunicação nessas Conferências é alguma coisa bastante diferente do que se faz no Governo. O que se propõe hoje é uma rede pública de entidades, uma rede que não é governamental, é uma rede que tenha que dar financiamento e apoio para projetos governamentais, não-governamentais, para pequenos projetos nos municípios; quer dizer, isto tudo está sendo dito desde a $9^{\text {a }}$ Conferência Nacional de Saúde. $\mathrm{Na} 8^{\mathrm{a}}$ Conferência a gente teve uma carta de princípios, dentre os quais que, para se ter saúde tem que se ter liberdade de expressão, não sei se alguém já prestou atenção, ou seja, direito à comunicação.

Esse direito de comunicação vem sendo vocalizado desde as cartas internacionais de Ottawa, etc. etc., que acabaram mobilizando, se ajustando às necessidades dos movimentos sociais e que a população tem que ter expressão na esfera pública de seus problemas. Então essa questão de uma política pública, quer dizer, não se está propondo ou não está se discutindo ou fazendo uma crítica exclusivamente à política de governo, mas está sendo vocalizado uma política pública de comunicação. Hoje em dia você tem financiamento do FUSC, do Fundo pela Universalização das Comunicações, e o que vem emergindo do debate das Conferências Nacionais de Saúde, das entrevistas com Conselheiros de Saúde, é um belíssimo de um projeto político, de política pública mesmo de comunicação. Eu queria só colocar a minha preocupação de não fechar o debate da comunicação, em um meio, em uma mídia, ou no jornal, ou numa televisão, até porque o que hoje está colocado no cenário das tecnologias é uma convergência de todos os meios, e você vê em cada pedacinho do país, em cada núcleo familiar, classe média, classe média baixa, acesso a tecnologias que a gente não imaginava que a população fosse um dia ter acesso.

Temos que prestar atenção no que está acontecendo no cenário das políticas de comunicação de maneira mais ampla, e tentar analisar de que forma podemos investir recursos para fortalecer essas outras vozes, que estão há bastante tempo apagadas do cenário político nacional. Só pra citar só mais um último exemplo, o Movimento dos SemTerra, e é um dos movimentos, por exemplo, que está conseguindo a partir das estratégias 
que tem, de organização, claro, ela é permeada por estratégias bastante interessantes de comunicação não só em rede, mas de conseguir furar o cerco da mídia, por exemplo. Colocar galinhas, porcos, etc., no Gabinete do Ministro às vezes é uma estratégia pra quem não consegue chegar a lugar nenhum, e um dos espaços interessantes de reflexão.

Acho que a gente tem, nessa relação entre comunicação e política, que pensar na comunicação e nas estratégias possíveis de manter movimentos sociais mais visíveis, discursos excluídos com mais visibilidade na esfera pública e mantê-los não só por um tempo efêmero, mas de ver como é que essa discursividade que está excluída da esfera pública consegue emergir e permanecer por mais tempo e permanecer polemizando as questões não só de saúde, mas do campo das outras políticas sociais, afinal de contas estamos falando de intersetorialidade o tempo todo.

\title{
TOWARDS A PUBLIC POLICY OF COMMUNICATION IN HEALTH
}

\begin{abstract}
Communication is a strategic issue in case of public policies, particularly health policies. The mass media, mainly television, spread news about health with great emphasis on the clinical and biomedical discourse. These issues are generally related to interests of large equipment, pharmaceutical and medical service companies, and they even determine the programming agenda of public communication organizations, such as public educational TV channels. Therefore, research and studies are needed in order to bring to the public arena the broadened concept of health in the light of promotion and as a right of all citizens. The right to communication has been expressed by community sectors and healthcare professional groups, who are committed to including discourses that are excluded from the media with the purpose of democratizing information.
\end{abstract}

KEYWORDS: health, communication, public policies, social movements, journalism. 